\title{
Gender and hemispheric specialization differences in the learning of Morse code letters
}

\author{
PIERRE CORMIER, CAROL TOMLINSON-KEASEY, and DAVID C. GEARY \\ University of California-Riverside, Riverside, California
}

\author{
(Ronald T. Kellogg, Sponsor)
}

\begin{abstract}
This study investigated changes in hemispheric specialization through five phases in the learning of a novel linguistic code. Naive subjects $(N=56)$ were taught the Morse code equivalents for eight letters. After each phase, a true/false reaction time verification paradigm was used for code-letter combinations presented to the left or right visual field. Reaction times and accuracy were analyzed separately. A significant interaction between sex, responding hand, and visual field was found when reaction times were measured $[F(1,52)=3.95, p=.052]$. When accuracy was analyzed, a significant interaction between sex and test phase was found $[F(4,216)=2.80, p<.05]$. The results suggest that, in terms of hemispheric specialization, males and females learn a new linguistic code differently. Implications for alternative theories of the development of hemispheric specialization are discussed.
\end{abstract}

Few studies of hemispheric specialization have dealt with learning. Beaumont and Dimond (1973; Dimond \& Beaumont, 1974) examined the capacity of each hemisphere for learning verbal associations and concluded that the left hemisphere was able to learn from unilateral and bilateral inputs and that the right hemisphere was able to learn only from unilateral input.

In an experiment that traced hemispheric specialization during the learning of new material, Gordon and Carmon (1976) required subjects to learn four sets of symbols that represented digits: the familiar set of numerals, numerals in gothic script, numerals in binary code, and numerals in an artificial code from the symbol substitution test of the Wechsler Adult Intelligence Scale. They found (1) that naming was consistently faster in the right visual field for familiar numbers and (2) that the visual field advantage in naming speed was related to the number of trials for binary numbers. Binary numbers were named faster when presented in the left visual field during the first half of the experiment but were named faster when presented in the right visual field during the second half. These findings supported Gordon and Carmon's contention that the right hemisphere is more involved when stimuli are novel or in the early stages of learning. Other findings that support this view have shown that females move from a left visual field advantage, or no advantage, for semantic de-

The authors would like to thank Judy A. Beaudin, Regina Hovey, and Ann Englert for their assistance with data collection, and Ron Kellogg for comments on an earlier draft of this article. Support for this study was provided by the Natural Sciences and Engineering Research Council of Canada and Québec's Formation de Chercheurs et Action Concertée scholarships to the first author and by an intramural research grant from the University of California-Riverside to the second author. Address correspondence to the first author, who is now at the Department of Psychology, Acadia University, Wolfville, Nova Scotia BOP 1X0, Canada. The third author is now at the Department of Psychology, The University of Missouri at Rolla, Rolla, MO 65401-0249. cisions to a right visual field advantage over blocks of trials (Bradshaw \& Gates, 1978), and that Hebrew children who are non-native speakers of English begin with a left visual field advantage for the recognition of English nouns and gradually change to a right visual field advantage as they accumulate years of experience with English (Silverberg, Bentin, Gaziel, Obler, \& Albert, 1979).

In the present study, we examined the effect that training had on hemispheric specialization by mapping patterns of hemispheric specialization from the initial learning stages of a task to a level of automatic functioning. The task selected was learning eight letters of the Morse code. Morse codes are novel to most undergraduate students, yet they can be easily associated with a familiar linguistic code, the alphabet. This study was designed to assess a subject's hemispheric specialization at different points in the acquisition of this new code. In addition, we examined the relationship between gender and patterns of hemispheric specialization during the course of learning because there is support for differential lateralization in the sexes (Kimura, 1987; McGlone, 1980), and earlier learning studies (Beaumont \& Dimond, 1973; Dimond \& Beaumont, 1974; Gordon \& Carmon, 1976) did not take gender into consideration.

\section{METHOD}

\section{Subjects}

Subjects were 56 college students ( 28 males and 28 females) enrolled in introductory psychology classes at a major western university. All subjects received extra course credit and $\$ 8$ for participating in the experiment. All subjects were right-handed, as determined by the Edinburgh Inventory (Oldfield, 1971), and had normal or corrected-to-normal vision. None of the subjects reported having any first-order relatives who were left-handed or any knowledge or experience with Morse code.

\section{Stimuli and Apparatus}

Two sets of Morse code stimuli were constructed for this study, one set for the learning phase and an additional set for the testing of 
hemispheric specialization. Both sets included the eight three-symbol combinations of International Morse Code (i.e., d, g, w, h, r, o, s, u). The fact that all the letters were represented by three symbols, as opposed to one or two, meant that the complexity of the stimuli was controlled and that the letters could be presented in the same visual window during the testing for hemispheric specialization.

The set of stimuli was constructed from the Cartesian product $(8 \times 8)$ of the above-mentioned three-symbol combinations and the respective letters. This yielded a set of code-letter combinations that included all eight correct combinations and an additional 56 erroneous combinations for each visual field. Each stimulus was mounted on a $13 \times 18 \mathrm{~cm}$ card, using 24-point black Letraset Helvetica Medium letters and symbols. A randomly selected number between 2 and 9 was centered at the fixation point. The code-letter pairs were placed $1.6^{\circ}$ either to the left or the right of the fixation point, and displaced $3.0^{\circ}$ total. The letter was centered above the code.

Stimuli were presented on a Gerbrands Scientific Prototype threechannel tachistoscope coupled to a Lafayette timer (Model 54014). The timer ensured the collection of reaction times (RTs) with an accuracy of $\pm 1 \mathrm{msec}$. Two telegraph keys were placed in front of the subject.

\section{Procedure}

The actual experiment included five phases. During each phase subjects were required to learn the Morse code equivalent for eight alphabetic letters, as noted earlier. After each learning phase, hemispheric specialization for these code-letter combinations was tested using the tachistoscope. The learning phases and the testing took place in adjacent laboratory rooms.

During each of the learning phases subjects sat in front of an Apple II+ microcomputer, which presented eight code-letter pairs in the first learning phase and 16 pairs (each of the orginal 8 pairs randomly presented twice) in the remaining four learning phases. Each code-letter pair was presented individually at the center of the computer monitor with the letter centered above the code. When each code-letter pair appeared on the screen, subjects were instructed to say the Morse code and the presented letter. For example, if - - and the letter $U$ appeared, the subject would say, "Dot, dot, dash is a U." Subjects controlled the speed of the presentation by pressing a key when they were finished reading the code-letter pair.

Assessments of hemispheric specialization followed each of the five learning phases. Each hemispheric assessment sequence consisted of 16 trials in each of the two visual fields. Eight of the 16 stimuli were the correct pairings of the just-rehearsed code-letter combinations, and the remaining 8 stimuli were incorrect pairings. The incorrect pairings were drawn at random from the set of 56 possible erroneous pairings, with the following constraints: within a set of 32 trials, no sequence of 4 stimuli in the same visual field or of 4 correct or incorrect stimuli was allowed.

Each test trial began with subjects viewing a fixation circle presented in the center of one of the tachistoscope channels for a duration of $1,000 \mathrm{msec}$ and was immediately followed by the presentation of a second field. Here, a number at the fixation point and a code-letter pair on either the right or the left side of the fixation point was presented for a duration of $100 \mathrm{msec}$.

Subjects were instructed to focus on the fixation circle and then the digit and to indicate whether the code-letter pairs were correct or incorrect by pressing one of two telegraph keys. For half the subjects (14 males and 14 females), the "correct" key was on the right side and the "incorrect" key was on the left side. This key placement was reversed for the other half of the sample. After subjects had indicated whether the pair was correct or not, they reported the fixation digit. Trials with wrong reports of the fixation digit were repeated, in the order they occurred, at the end of the sequence of 32 trials.

The first three learning phases were completed in Session 1 and the last two phases in Session 2, which was conducted 3 days after Session 1 . Each of these sessions lasted approximately $1 \mathrm{~h}$.

\section{RESULTS}

The central question of this study concerned differences in hemispheric specialization across the five learning phases. To assess these differences, we performed two analyses of variance (ANOVAs): the first used mean correct reaction time (RT) as the dependent measure, and the second used Bryden and Sprott's (1981) laterality coefficient.

Mean correct RT was obtained from individual RTs calculated from stimulus onset to key depression (see Table 1). Mean correct RTs were analyzed by means of a 2 (sex) $\times 2$ (responding hand) $\times 2$ (visual field) $\times 5$ (phases of learning) mixed ANOVA. Gender and responding hand were between-subject factors, and visual field and phases of learning were within-subject factors.

The main effects of gender $[F(1,52)=4.21, p<.05$, $M S e=2,599,344.54]$ and phase $[F(4,208)=13.70$, $p<.05, M S e=232,096.69]$ were significant. Males were slower $(M=1,982 \mathrm{msec})$ than females $(M=$ $1,421 \mathrm{msec})$, and there was a linear decrease in RTs across learning phases $[F(1,208)=53.99, p<.05$, MSe $=232,096.69]$, indicating that subjects were giving correct answers more quickly as the experiment progressed. This significant result indicates that learning was occurring. [Nonlinear trends were not significant: $F(3,208)=$ $1.32, p>.05, M S e=232,096.69$.]

A marginally significant interaction between gender, responding hand, and visual field $[F(1,52)=3.95, p=$ $.052, M S e=36,834.12]$ indicated that differences in RT

Table 1

Means and Standard Deviations of Correct Reaction Times to Stimuli Presented in the Left and Right Visual Fields at Each Phase of the Study by Each Experimental Group

\begin{tabular}{|c|c|c|c|c|c|c|c|c|c|c|c|}
\hline \multirow[b]{3}{*}{ Group } & \multirow{3}{*}{$\begin{array}{l}\text { Visual } \\
\text { Field } \\
\end{array}$} & \multicolumn{10}{|c|}{ Phase } \\
\hline & & \multicolumn{2}{|c|}{1} & \multicolumn{2}{|c|}{2} & \multicolumn{2}{|c|}{3} & \multicolumn{2}{|c|}{4} & \multicolumn{2}{|c|}{5} \\
\hline & & $\boldsymbol{M}$ & $S D$ & $M$ & $S D$ & $\boldsymbol{M}$ & $S D$ & $M$ & $S D$ & $M$ & $S D$ \\
\hline \multirow[t]{2}{*}{ Female RH } & Left & 1600 & 588 & 1466 & 574 & 1333 & 547 & 1277 & 470 & 1291 & 518 \\
\hline & Right & 1614 & 584 & 1519 & 687 & 1344 & 535 & 1258 & 441 & 1262 & 477 \\
\hline \multirow[t]{2}{*}{ Female LH } & Left & 1969 & 690 & 1792 & 669 & 1743 & 597 & 1503 & 544 & 1532 & 639 \\
\hline & Right & 1850 & 619 & 1830 & 738 & 1757 & 671 & 1499 & 474 & 1461 & 528 \\
\hline \multirow[t]{2}{*}{ Male RH } & Left & 2070 & 841 & 1995 & 703 & 1890 & 718 & 1629 & 555 & 1506 & 540 \\
\hline & Right & 1949 & 816 & 1894 & 813 & 1719 & 658 & 1698 & 641 & 1590 & 643 \\
\hline \multirow[t]{2}{*}{ Male LH } & Left & 2019 & 634 & 1964 & 745 & 1790 & 616 & 1718 & 625 & 1668 & 636 \\
\hline & Right & 2091 & 893 & 1892 & 613 & 2015 & 839 & 1782 & 677 & 1613 & 604 \\
\hline
\end{tabular}

Note- $\mathrm{RH}=$ right hand. $\mathrm{LH}=$ left hand. 
varied as a function of visual field of presentation, gender, and response hand. Post hoc comparisons of means (see Table 1) using Scheffé's procedure (Kirk, 1982: the critical difference between any two means at $p<.05$ was $117 \mathrm{msec}$ ) indicated that the interaction resulted not from differences between the visual fields within the other conditions, but from differences between the other conditions within the visual fields. Females who responded with their right hands were faster than females who responded with their left hands in both the right $\left(M_{\mathrm{r}}=2,499 \mathrm{msec} ; M_{1}\right.$ $=2,779 \mathrm{msec})$ and left $\left(M_{\mathrm{r}}=2,494 \mathrm{msec} ; M_{1}=\right.$ $2,808 \mathrm{msec}$ ) visual fields. For males, in contrast, $\mathrm{RT}$ did not differ across response hand in the right $\left(M_{\mathrm{r}}=\right.$ $\left.2,870 \mathrm{msec} ; M_{1}=2,979 \mathrm{msec}\right)$ or left $\left(M_{\mathrm{r}}=2,918 \mathrm{msec}\right.$; $M_{1}=2,931 \mathrm{msec}$ ) visual field. In sum, the interaction resulted primarily from very fast RT by the group of females using right hands to respond.

Overall, this analysis indicates little in the way of hemispheric specialization as measured by RT. It does, however, indicate that subjects learned Morse code as the experiment progressed and that males and females responded quite differently to the task.

Bryden and Sprott's (1981) laterality coefficient is based on the left-right ratio of correct answers. This coefficient has the advantage of not being affected by the subject's overall performance. The average laterality coefficients for males and females at each phase of the study are presented in Figure 1.

Subjects' laterality coefficients were analyzed with a 2 (gender) $\times 2$ (responding hand) $\times 5$ (phases of learning) mixed ANOVA. Responding hand did not have any effect on the laterality coefficients $(p>.25)$ and was eliminated from subsequent analyses. A significant gender $\times$ learning phase interaction was found $[F(4,216)=2.68$, $p<.05, M S e=0.61948]$. Treatment $\times$ trend contrasts

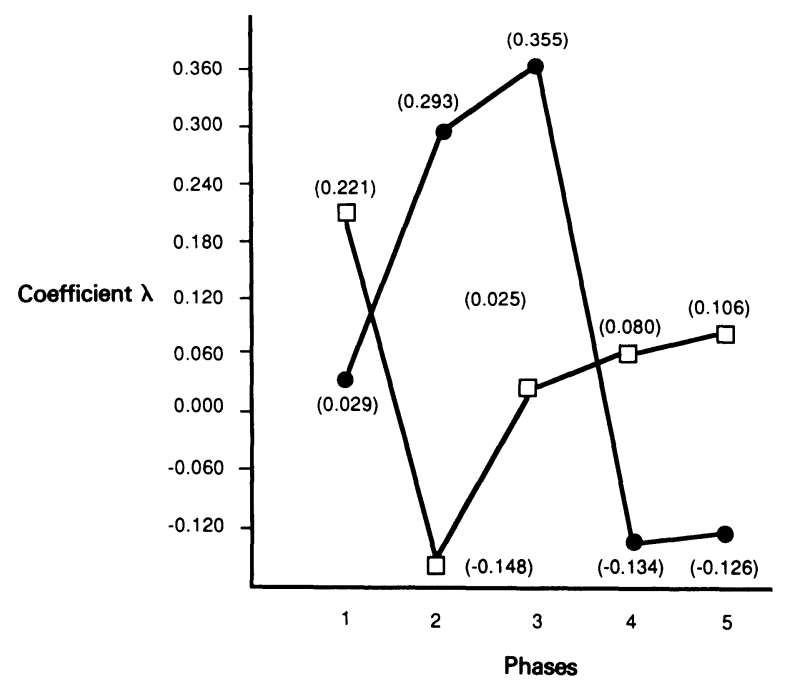

Figure 1. Average lambda laterality coefificient for the male (squares) and female (circles) groups at each phase of learning. were calculated to analyze this interaction (Kirk, 1982). Males and females did not differ on the linear or quartic trends $[F(1,216)=1.09, p>.05, M S e=0.61948$, and $F(1,216)=0.00, p>.05, M S e=0.61948$, respectively]. There were significant differences, however, for males and females on the quadratic and cubic trends $[F(1,216)=5.61, p<.05, M S e=0.61948$, and $F(1,216)=4.02, p<.05, M S e=0.61948$, respectively].

As can be seen in Figure 1, males began the study with a right visual field advantage that was followed by a left visual field advantage at Phase 2 and a reappearance of the initial right visual field advantage in Phases 3,4 , and 5. In comparison, females began the study with no visual field advantage, presented a right visual field advantage at Phases 2 and 3 , and presented a left visual field advantage at Phases 4 and 5. The differences between the two hemispheres are greater for the women, especially in the earlier phases of the experiment. Thus, the pattern of visual field advantages for accuracy, as assessed by Bryden and Sprott's (1981) laterality coefficient, follows a quadratic trend in males and a cubic trend in females. More important, the pattern of changes in laterality coefficients in Figure 1 indicates that hemispheric advantages for verifying code-letter combinations were in obviously different directions for males and females as they progressed in their learning of the Morse code.

\section{DISCUSSION}

The patterns of hemispheric specialization during the learning of Morse code differed according to whether RT or accuracy was examined. No right or left visual field differences were observed across learning phases for RTs, but hemispheric advantages were present when coefficients of laterality-taking into account the accuracy in each visual fieldwere used as a measure of hemispheric specialization.

The finding of no changes in hemispheric advantages for RT stands in contrast to Gordon and Carmon's (1976) study. The use of different stimuli (Morse code vs. different codes for numerals), different tasks (verification vs. naming), and different ways of calculating hemispheric differences in reaction time may account for this discrepancy in results. Several reviews have indicated that hemispheric specialization is not consistent across stimulus types or tasks (Beaumont, 1982; Boles, 1984; Sergent, 1983).

Hemispheric advantages in accuracy varied as a function of gender and phase of learning. Indeed, the laterality coefficient for males and females moved in opposite directions as they learned the Morse code equivalents for each of the eight letters. Male subjects changed from a right hemisphere advantage to a left hemisphere advantage over the last four phases of the learning sequence. This pattern of an increasing left hemisphere advantage fits Moscovitch's (1979) position that hemispheric specialization occurs in the last steps of the information processing sequence. As the left hemisphere becomes more skilled in the task, it gains a performance advantage over the right hemisphere. In contrast, female subjects shifted from a left hemisphere advantage to a right hemisphere advantage in the last two phases of learning. This pattern of shifts in hemispheric advantage is consistent with Luria's (1973) position that the right hemisphere is more specialized for automatic processing. The two patterns of hemispheric specialization observed in this study give support to two different positions on hemispheric specialization, one for each sex.

The presence of a gender difference could be attributed either to differences in the way the brain is organized for each sex (Kimura, 1987; McGlone, 1980) or to the way females and males reacted to the learn- 
ing task. More detailed studies identifying subjects' strategies would be necessary in order to disentangle these two hypotheses. Two studies (Metzger \& Antes, 1976, Experiment 2; Seamon \& Gazzaniga, 1973) showed that an instruction to code information with words or with an image yielded opposite visual field advantages in a word-picture matching task, suggesting that hemispheric advantages may be related to task demands. Moreover, Metzger and Antes (1976, Experiment 1) observed that, in a word-matching task, females responded faster than males when they were required to verbally code the information, and males responded faster than females when they were required to form a mental image of the two words to memorize. Females and males can respond differently to instructions, and, in the present study, this type of differential response might have led to the different hemispheric advantages.

Although the findings on RT and accuracy differed in this study, they can be interpreted as complementary. Each set of findings points to gender differences. The RT data point to gender differences in responding, which were accompanied by gender differences in visual field accuracy. Males are thought to have more lateralized linguistic functions than females (McGlone, 1980); therefore, their left hemisphere might be quicker at coding a linguistic function after the initial steps of learning, as was observed in this study, whereas the more flexible lateralization of function in females would account for their pattern of results. These findings suggest that male and female hemispheric specializations are different and may be related to differences in the way males and females learn a task.

\section{REFERENCES}

Beaumont, J. G. (1982). Developmental aspects. In J. G. Beaumont (Ed.), Divided visual field studies of cerebral organization (pp. 116128). London: Academic Press.

Beaumont, J. G., \& Dimond, S. T. (1973). Transfer between the cerebral hemispheres in human learning. Acta Psychologica, 37, 87-91.

Boles, D. B. (1984). Sex in lateralized tachistoscopic word recognition. Brain \& Language, 23, 307-317.

Bradshaw, J. L., \& Gates, E. A. (1978). Visual field differences in verbal tasks: Effects of task familiarity and sex of subject. Brain \& Language, 5, 166-187.

BRYDEN, M. P., SPROTT, D. A. (1981). Statistical determination of degree of laterality. Neuropsychologia, 19, 571-581.

Dimond, S. T., \& BeaumonT, J. G. (1974). Hemispheric function in paired associate learning. British Journal of Psychology, 65, 275-278.

GoRDON, H. W., \& CaRmoN, A. (1976). Transfer of dominance in speed of verbal response to visually presented stimuli from right to left hemisphere. Perceptual \& Motor Skills, 42, 1091-1100.

KIMURA, D. (1987). Are men's and women's brains really different? Canadian Psychology, 28, 133-147.

KIRK, R. E. (1982). Experimental design (2nd ed.). Belmont, CA: Brooks/Cole.

LURIA, A. R. (1973). The working brain (Basil Haigh, Trans.). New York: Penguin Press.

McGlone, J. (1980). Sex differences in human brain asymmetry: A critical survey. Brain \& Behavioral Sciences, 3, 215-263.

Metzger, R. L., \& ANTEs, J. R. (1976). Sex and coding strategy effects on reaction time to hemispheric probes. Memory \& Cognition, 4, 167-171.

Moscovitch, M. (1979). Information processing and the cerebral hemispheres. In M. S. Gazzaniga (Ed.), Handbook of behavioral neurobiology: Vol. 2. Neuropsychology (pp. 379-446). New York: Plenum Press.

OLDFIELD, R. C. (1971). The assessment and analyses of handedness: The Edinburgh Inventory. Neuropsychologia, 9, 97-113.

Seamon, J. G., \& Gazzaniga, M. S. (1973). Coding strategies and cerebral laterality effects. Cognitive Psychology, 5, 249-256.

SERGENT, J. (1983). The role of the input in visual hemispheric asymmetries. Psychological Bulletin, 93, 481-514.

Silverberg, R., Bentin, S., Gazlel, T., Obler, L. K., \& Albert, M. L. (1979). Shift of visual field preference for English words in native Hebrew speakers. Brain \& Language, 8, 184-190.

(Manuscript received for publication March 2, 1988.) 